\title{
Current arrangements for teaching medical ethics to undergraduate medical students
}

\author{
D J Bicknell Department of Psychiatry, St George's Hospital Medical School
}

\section{Author's abstract}

Those teachers in contact with medical students from pre-clinical days onwards will impart their ethical views by example and by precept, but such learning by 'osmosis' is insufficient. There is a knowledge base to be imparted which will enrich the understanding of ethical judgements on clinical problems seen during the undergraduate years. However, the learning process continues after qualification and in particular the doctor's capacity to make ethical clinical judgements will evolve with maturity and experience. It is essential therefore that students see their teachers willing and able to debate ethical issues at the postgraduate level.

In June, 1981 at St George's Hospital Medical School a small informal working party was set up to look at the teaching of medical ethics. The stimulus for this had come from a group of medical students who had been exposed to the dilemmas and the discussions that surround infantile euthanasia and who felt they had not been able to follow through the discussion as they would have wished. The working party consisted of the Professors of Geriatrics, Psychiatry, Paediatrics and the Psychiatry of Mental Handicap, and two chaplains, one from the hospital and one from the medical school. In view of the acknowledged gap in the curriculum, we felt it was our duty to look at the topics that should be taught and learned, the methods of teaching and the methods of checking the knowledge acquired.

The working party was reminded that first-year medical students often came straight from school. Some had experienced factually-based and sometimes authoritarian education and, as personal tutor to some first-year students, I can vouch for the immaturity of some. In five years we expect them to begin the change towards being thoughtful, discriminating people who are comfortable in the pale shades of grey between the black and the white and who value those questions that have no simple answers: a process of change, of course, that continues throughout the postgraduate years. We also expect them to acquire an ever increasing mass of knowledge and skill. If they have ethical viewpoints

\section{Key words}

Medical ethics education; medical ethics. when they come to medical school, they have probably gained them from their parents, from their school $\rightarrow$ teachers, from their religious teachers, or perhaps from: political ideologists. It seemed to us that very rarelyin had the first-year medical student experience of $\circ$ life's tragedies and dilemmas which would have given these views a particular personal shape.

Within our medical school the working party identified three groups of students: the first is a group $\frac{\rho}{\supset}$ who are interested in ethics, very often belonging to the $\overrightarrow{0}$ religious organisations, through which they have had aog chance to debate ethical issues; a second group are curious and want to learn more about ethics but will certainly reject such learning if it comes under the label of 'religion', and a third group see ethics as having very little relevance especially when they think theyo can pass examinations without ethical knowledge.

The working party asked a number of questions, $\overrightarrow{\overrightarrow{0}}$ such as: How are we going to teach medical ethics? 3 (The alternatives to the large lecture theatre include? small groups, debates, the tutorial, the case conference? and the ward round). Where are the books and the journals to which students may turn? Do we have a film.

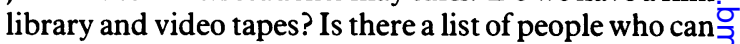
counsel and support students? Is there a forum in the medical school for highly topical ethical issues to be raised quickly before society determines the trend and the response? Is osmosis sufficient? When do we teach은 - the first year is certainly not too early to increase self $-\frac{7}{0}$ awareness and to show the range of choices in decisionmaking. The final year is a good time to draw together N the threads and to anticipate the dawning doctorpatient relationship.

In our programme the formal teaching is at the $\mathrm{N}^{\mathrm{E}}$ beginning of the clinical years but we hope that there will be an increasing spread of informal teaching throughout the time spent at the school.

Turning to the syllabus, what are we going to teach? $?^{\text {? }}$ We believe there is a base of knowledge to be acquired $\frac{T}{+}$ from which useful and productive discussions can $\frac{\mathbb{D}}{\stackrel{D}{0}}$ stem. We identify the syllabus as the role of religion's, $\frac{?}{\mathbb{P}}$ law's and society's values in the formation of ethical $\varrho$ codes and in particular we mention the role of the General Medical Council. There are the principles of 8 decision-making: there is the personal code ofo behaviour; there is paternalism versus autonomy and흥. 
the doctor's own responsibility for the updating of his or her knowledge and for his or her own lifestyle. We deal also with more general issues including the allocation of resources, the role of private practice, medico-legal proceedings, the doctor and patient in research, the role of the doctor in relationship with the media, the doctor in politics, the doctor as a teacher and the doctor as an agent of social change. The base of knowledge can be acquired through didactic lectures but the formulation of personal values occurs in the clinic and at the bedside.

This complicated syllabus may be divided into four more simple areas: the doctor and his patient, the doctor and himself, the doctor and the profession and the doctor and others.

At St George's Hospital Medical School there are four didactic lectures. The core of each of these lectures is, respectively: decision-making; confidentiality; the viewpoint of a patient in teaching, treatment and research (given by somebody who has recently been a patient); and, fourthly, the misuse of medicine. In addition there is an annual medical ethics lecture, which takes place in the evening, when an outside speaker of repute lectures on a topic of his or her choice.

A number of areas are covered in our small-group work, including the teaching of interviewing skills, at the beginning of the clinical course, and we try to use this time as an opportunity for students to become more sensitive about the dynamics of the dialogue between the doctor and the patient. We also try to encourage the student to understand what it is like to be a severely disabled person in today's world.

Debates take place, particularly in psychiatry, where such issues as the sanctity of life, autonomy and self-determination are very carefully prepared and hotly debated.

In terms of examination the first ethics question appeared in the psychiatry paper in our Finals in 1983.

In conclusion, we believe that ethics cannot be imbibed solely through the process of osmosis; osmosis will, of course, continue to happen but we cannot rely on that as a total learning exercise. Neither do we want medical ethics to become an unpopular and unexamined sub-specialty in the medical school. We feel it must be taught and learned using the whole range of educational technology. Above all, we must raise the awareness of all clinicians and teachers to the need to make the ethical implications of their subject an intrinsic part of the knowledge required. The best way of doing this is, we feel, to increase the sensitivity to ethical issues at a postgraduate level: at our conferences and postgraduate meetings, do we discuss and debate the ethical issues with which we are wrestling and in particular are we prepared to expose our uncertainties and our inadequacies to the juniors and to the medical students? If the ongoing process of medical education contained an ethical sensitivity, we would have the confidence and sense of urgency to hand this on to those who are just starting in medicine.

(Continued from page 21)

\section{References}

(1) Kopelman L. Cynicism among medical students. Fournal of the American Medical Association. 1983; 250: 2006-2010.

(2) Lindy J D, Green B L, Patrick M. The internship. Some disquieting findings. American journal of psychiatry 1980; 137, 1: 76

(3) Mawson D, Marks I M, Ramm L, Stern R S. Guided mourning for morbid grief. British journal of psychiatry 1981; 138: 185-193. 